\title{
A importância do endomarketing para a comunicação interna
}

\author{
RESUMO
}

Sarah Cristina Martins Gonçalves Lima

sarah.cris8@email.com

Faculdade Projeção (PROJEÇÃO), Guará, Distrito Federal, Brasil

\section{José Airton Mendonça de Melo}

jose.melo@projecao.br

Projeção

Centro Universitário Projeçãa

(UNIPROJEÇÃ
O presente artigo tem como objetivo identificar e estudar a percepção dos colaboradores de um órgão federal sobre as ferramentas do endomarketing e comunicação. Trata-se de uma pesquisa exploratória, cujas técnicas de coleta de dados empregada foram pesquisa bibliográfica e de campo, nesta última o instrumento de coleta de dados foi um questionário aplicado a trinta funcionários de um órgão público prestador de serviço para a presidência, integrando efetivos e terceirizados. A análise dos resultados mostra que precisa haver uma melhoria na comunicação interna do órgão federal estudado. E em relação ao endomarketing, é necessário utilizar técnicas para que os funcionários possam obter o melhor rendimento no seu setor, fazendo-os entender a importância de uma melhoria de comunicação entre um setor e outro, para assim ter mais eficiência no processo produtivo.

PALAVRAS-CHAVE: Endomarketing. Comunicação. Comunicação interna 


\section{INTRODUÇÃO}

O endomarketing é uma ferramenta nova na área do marketing, introduzido na década de setenta por Saul Bekin, segundo Grönroos (2003). Essa ferramenta consiste num processo de gerenciamento voltado para dentro da empresa, fazendo com que o funcionário seja visto com atenção e sinta-se parte da empresa, deixando o motivado para desempenhar sua função.

A comunicação interna deve ser com transparência entre todos os setores, assim como as ações que precisam ser gerenciadas para o funcionário da organização, favorecendo o clima organizacional e agregando valor para o ambiente interno do órgão público.

O tema abordado neste artigo é a importância do endomarketing para a comunicação interna de um órgão público, prestador de serviço para a Presidência, um dos serviços realizado é a elaboração do diário oficial. Localizado no setor de indústria gráfica, Brasília-DF, a pesquisa foi realizada no ano de 2017, foi escolhido pelo fato de analisar e perceber essa falta de diálogo mais transparente entre o setor no órgão estudado. Foi observado que muitos dos trabalhos que são feitos, principalmente na área de licitação, acabam retornando para o setor justamente por não se ter essa comunicação mais clara, fazendo com que haja mais lentidão no serviço desenvolvido, sendo que algumas licitações têm um grande teor de urgência e acabam não sendo solucionadas por essa falta de comunicação. Logo, o problema de pesquisa é como o endomarketing pode melhorar este processo?

Tendo como base esse problema detectado, o objetivo geral deste artigo é identificar e estudar a percepção dos colaboradores de um órgão federal sobre as ferramentas do endomarketing e comunicação interna. E para poder alcançá-lo, será necessário levantar a fundamentação teórica sobre o endomarketing e comunicação interna que responda e fundamente uma resposta ao problema levantado no estudo, identificar e conceituar os métodos de pesquisa, o públicoalvo a ser atingido, e desenvolver um diagnóstico sobre a situação do estudo de caso/problema.

Sobre a importância deste estudo, observa-se a definição dada por Marchiori (1995), deque a incorporação do público interno é essencial, visto que quando os seus funcionários têm as mesmas informações e entendem que fazem parte diretamente do ambiente organizacional, e que detém valores comuns e dividem os mesmos interesses, obtém-se resultados positivos.

Tendo uma boa comunicação interna, se consegue mais agilidade nos trabalhos a serem feitos e serviços pendentes, fazendo com que os processos não sejam tão burocráticos e demorados e assim se consegue eficiência e agilidade nos trabalhos desenvolvidos no órgão público. Com essa melhoria na comunicação interna, o funcionário tende a ter uma melhor relação no seu ambiente de trabalho que se resultará em melhor atendimento ao cliente externo, e que segundo a teoria de Maslow (1943, apud MAXIMIANO, 1995), quando o funcionário tem sua autoestima realizada no trabalho como consequência fora do trabalho, proporcionará melhor convivência com a família, amigos e melhor relacionamento na comunidade.

O artigo tem como propósito apresentar soluções para o problema já diagnosticado, que é a falha de comunicação pelo órgão público em estudo. Para alcançar esse objetivo, foi aplicado o tipo de metodologia exploratória com as 
técnicas coleta de dados, uma pesquisa bibliográfica e estudo de campo na modalidade estudo de caso. O questionário foi aplicado, entregue em mãos à trinta funcionários de um órgão público entre servidores públicos e funcionários terceirizados, sendo respondido e entregue no mesmo dia

Neste sentido, o artigo está estruturado em quatro seções, além desta Introdução. A primeira compreende a fundamentação teórica, que aborda as principais teorias sobre endomarketing e comunicação interna. A segunda trata da metodologia da pesquisa. A terceira seção é a análise, que faz uma descrição e discussão analítica dos dados e informações levantadas ou observadas no desenvolvimento da pesquisa. Na última é apresentada a conclusão do estudo.

\section{REVISÃO TEÓRICA}

A presente seção apresenta a revisão teórica acerca do endomarketing, abordando seu conceito e algumas das correntes teóricas que buscaram analisar o fenômeno desta ferramenta no decorrer do tempo, apresenta-se ainda sua relação com a comunicação interna destacando-se características relevantes que diferenciam os dois conceitos. Logo, essa seção tem o propósito de fundamentar o objetivo do trabalho de levantar a fundamentação teórica sobre endomarketing e comunicação interna que responda e fundamente uma resposta ao problema levantado no estudo.

\section{ENDOMARKETING}

Saul Bekin (2005), por meio da sua vivência no marketing, afirma que o termo endomarketing está fundamentado na importância da aprovação a estratégias de marketing voltadas para o público interno como diferencial para as organizações e o progresso mediante o comprometimento de todas as pessoas que fazem parte do processo produtivo da empresa. Para a obtenção de melhores resultados, Bekin (2005) propõe motivar o público interno a fim de que eles tenham uma razão pela qual trabalhar.

Kotler (1998) diz que o marketing interno é como uma tarefa difícil bemsucedida de contratar, treinar e motivar funcionários competentes que desejam receber bem aos consumidores e ele ainda evidencia que o marketing interno deve ocorre antes do externo.

Nesse sentido que Cerqueira (1994), diz que endomarketing são propostas e ações que a empresa deve executar para estabelecer um comprometimento dos funcionários com o desenvolvimento da organização.

No Brasil, segundo Brum (2005), o endomarketing surgiu oficialmente na metade da década de 80 , e se expandido no início da década de 90 , pois devido ao desejo que as empresas tinham de ser mais competentes que os sindicatos no sentido da comunicação com seus funcionários, surgiram então, o princípio de uma aproximação entre essas partes.

\section{Objetivo do endomarketing}


O principal objetivo do endomarketing é que todos do público interno compartilhem as mesmas ideias, metas, resultados. Isso implica seriamente no fracasso ou sucesso do empreendimento (BRUM, 1998).

Com isso, Bekin (2006) afirma que a empresa precisa conhecer seu público interno para poder comunicar os objetivos de forma adequada. Portanto isso não é uma tarefa das mais fáceis, pois as unidades das empresas precisam estar em harmonia. Para gerar essa harmonia precisa-se de ações de endomarketing, as quais são atividades e eventos voltados para a informação e integração do público interno, sendo as atitudes de endomarketing são decisões e iniciativas tomadas pela empresa e suas lideranças no sentido de proporcionar um maior e melhor nível de informação e de integração aos seus empregados, sempre com o foco no seu bem-estar.

Sendo assim, para gerar esse bem-estar e essa alegria no trabalho é necessário criar canais de comunicação que sejam abertos e diretos e respeitar as diferenças pessoais existentes, afirma Brum (2010). Pois com esse respeito, obtém-se incentivo e bom relacionamento com o empregado que gera comprometimento do mesmo, além do que o empregado consegue enxergar sua importância na empresa. Desta forma, a comunicação bem feita é basicamente a forma de fazer com o que o funcionário se motive e se sinta satisfeito.

Esta proximidade para com o cliente interno fará com que este se torne muito mais íntimo do processo de gestão e decisão empresarial e, injetará nele ainda uma dose de motivação e autoestima, sentimentos que podem ser decisivos para a realização de um trabalho eficiente e eficaz, objetivando assim as relações internas dentro da empresa integrando o fornecedor interno que, propicia uma melhoria na qualidade dos produtos (BEKIN, 1997).

Em síntese, com base no que foi dito pelos autores, endomarketing é uma ferramenta para que o público interno se sinta motivado e saiba sua importância para a empresa, gerando um entendimento no ambiente interno, para que todos compartilhem das mesmas ideias.

\section{COMUNICAÇÃO}

De acordo com Angeloni (2010), a comunicação organizacional é muito complexa, precisa-se entender que vários fatores podem influenciar na comunicação das empresas, sendo que as relações de trabalho são construídas através da comunicação. Com isso, para esse mesmo autor pode-se classificar a comunicação em interna e externa, sendo a externa integra a veiculação de informação que é emitida através da empresa para o mercado, fornecedores, consumidores. A interna visa integrar as comunicações dentro de uma empresa sendo o foco o público interno.

As duas comunicações são importantes para a empresa como expõe Bahia (1995), tanto a comunicação interna como a externa são essenciais para a empresa. E ainda diz que é importante para a organização tanto a opinião dos seus funcionários sobre o que produzem, quanto à opinião do mundo exterior para que possa se relacionar de forma eficaz com seus públicos. 
Com isso, Garcia (2006) expõe que, "a comunicação serve para produzir consenso, gerar aceitação e consentimento". Deste modo, ela está intimamente ligada ao público.

Com base no que foi mencionado pelos autores, a comunicação está ligada diretamente com as relações no trabalho, logo que, nossas conversas cotidianas, gestos comunicacionais fazem parte da comunicação.

\section{Objetivo do endomarketing}

A comunicação interna é a conexão da parte que transmite a mensagem e a parte que capta, ainda que a mensagem seja boa, se não for compreendida por outros, logo, não será proveitosa nem útil, afirma Casado (2002). Quer dizer, se não houver um bom entendimento não haverá compreensão no que está sendo comunicado.

De acordo com Rabaça (2001), a definição de comunicação interna vem a ser a forma de comunicação entre o órgão público e o seu público interno. Com isso, a comunicação precisa estar alinhada com o funcionário para que ele saiba as metas e objetivos da empresa.

Neste sentido, Brum (2007) defende que a comunicação que a empresa tem com o empregado, deve sair de cima da pirâmide cujo é a empresa e chegar até a base que é o funcionário, assim sendo a comunicação interna vem a ser à informação que é conduzida através de canais internos e das lideranças e o endomarketing é a notícia repassada com técnicas e estratégias de marketing.

Para colocar a comunicação interna em foco, existem vários instrumentos que podem ser adotados e inseridos, cada uma com a sua característica, eles devem estar adequados a total realidade da empresa. Brum (2010) faz uma relação de instrumentos que podem ser utilizados para o relacionamento:

- Vídeos: institucionais ou de apresentação dos produtos (têm como objetivo colocar os clientes internos com a realidade em que seu produto é utilizado)

- Manuais técnicos e educativos (seu objetivo é a apresentação de produtos, serviços, lançamentos, tendências em relação à tecnologia e a moda)

- Revistas com histórias em quadrinhos - Forma descontraída de trabalhar com a informação

- Jornal interno com a utilização de vários encartes, como, por exemplo, área de recursos humanos, projetos, produção e associação de funcionários. Pode ser utilizada, também, a versão do jornal de parede.

- Cartazes motivacionais, informativos e de forma de quebra-cabeça, sempre com o objetivo de passar novas informações para a equipe interna

- Canais diretos: reuniões com o diretor, presidência ou ouvidor interno palestras internas, programas para apresentar as novidades da empresa, as tendências e a evolução que a mesma teve.

- Grife interna: registro em roupas (uniformes), bonés e acessórios - memória, ou seja, o resgate da história da empresa, com o objetivo de passar da mesma, às pessoas que a desconhecem 
- Rádio interna: programas que passem diariamente trazendo informação/notícias da empresa.

- Vídeo jornal para a divulgação de lançamentos, pronunciamentos de diretores e gerentes.

- Intranet: Convenções internas: uso da equipe interna para divulgação de atividades.

Em síntese, com base no que foi falado pelos autores a comunicação interna não é somente emitir a comunicação, precisa-se compreender o que foi emitido. Logo, os instrumentos de comunicação têm uma parcela muito importante para que a comunicação interna tenha sucesso, tanto na emissão quando na recepção.

\section{ENDORMARKETING E COMUNICAÇÃO INTERNA}

Ferreira Filho, Pereira e Passos (2013) confirmam que há uma relação complementar entre o endomarketing e a comunicação interna, eles se confundem um pouco, mas de acordo com Brum (2011), "a comunicação interna vem a ser à informação que é conduzida através de canais internos e das lideranças e o endomarketing é a notícia repassada com técnicas e estratégias de marketing".

Conforme Inkotte (2000), no endomarketing a empresa é o próprio produto, que deve sempre ser melhorado, para que o cliente interno se sinta motivado e aumente o seu nível de comprometimento com a empresa. Seguindo o seu pensamento, no marketing interno, a empresa treina o funcionário e o motiva, tendo o foco no mercado externo. Um programa de comunicação interna, e endomarketing integrado tem reação imediata e intensa no relacionamento entre funcionários e empresa.

O funcionário que sabe, tem a consciência do seu real valor na empresa dá maior importância nas tarefas que realiza, executando seu papel com eficiência, pois a transparência na comunicação faz toda a diferença, o funcionário deve ser visto como o primeiro cliente. Tavares (2010, p. 19) acredita que "Melhorar a qualidade da comunicação interna e, consequentemente gerar motivação nos funcionários de uma empresa torna-se essencial para o resultado dos processos administrativos".

Assim concluísse que a comunicação interna e o endomarketing, andam juntos, são complementares, ambos têm o ambiente interno e os relacionamentos entre funcionários como objetivo principal. Tendo visto um pouco sobre endomarketing e comunicação interna, será visto agora a metodologia aplicada para o desenvolvimento e fundamentação da pesquisa.

\section{METODOLOGIA}

Esta seção aborda a metodologia empregada neste trabalho, cujo objetivo é identificar e estudar a percepção dos colaboradores de um órgão federal sobre as ferramentas do endomarketing e comunicação. Para tanto serão apresentados a seguir os métodos de pesquisa e os procedimentos técnicos de coleta de dados. 


\section{O MÉTODO}

O projeto tem como propósito apresentar soluções para problemas já diagnosticados. Foi adotado o tipo de pesquisa exploratória, de acordo com Mattar (1996), a pesquisa exploratória pretende fornecer o melhor conhecimento sobre o tema ou contrariedade de pesquisa em perspectiva. Esse tipo de pesquisa é muito útil quando for necessário aprofundar o assunto para se estabelecer melhor o problema.

Segundo Gil (1999), a pesquisa exploratória tem como objetivo fortalecer, resolver e mudar conceitos e ideias, a formulação de problemas mais precisos ou hipóteses pesquisáveis.

\section{AS TÉCNICAS DE COLETA DE DADOS}

Para atender o método anteriormente proposto, foram empregados como procedimentos de coleta de dados uma pesquisa bibliográfica e um estudo de campo na modalidade estudo de caso, este levantamento de campo é caracterizado pela investigação que além de ser documental, é realizado uma coleta de dados com pessoas próximas (FONSECA,2002).

A pesquisa bibliográfica permite uma maior obtenção de informações, além de conceder a utilização de dados separados em várias publicações, definindo o quadro conceitual que envolve o objeto de estudo proposto (GIL, 1994).

Segundo Gonsalves (2001), buscar a informação diretamente com o público exige que o pesquisador tenha um encontro mais direto, sendo assim há necessidade que o pesquisador vá ao espaço onde o fenômeno acontece, configurando assim um estudo de caso num órgão público. Roesch (2009) define este estudo como um plano de pesquisa que busca investigar um fenômeno contemporâneo.

\section{O PÚBLICO-ALVO}

O público alvo desta pesquisa foram os funcionários de um órgão público da esfera executiva no modelo de autarquia que é uma das mais antigas instituições públicas existentes do país, entretanto para os fins da pesquisa, apenas será tratado no presente trabalho os dados inerentes à estrutura funcional da instituição selecionada.

Este estudo de caso foi feito em apenas um setor do órgão estudado o qual é um setor da área de logística do órgão, no qual foram entrevistadas 30 pessoas, que correspondem à $70 \%$ dos colaboradores do setor, que possui no quadro de funcionários 43 pessoas, que ocupam o cargo de auxiliar administrativo e que fazem parte do quadro do órgão público, contemplando servidores efetivos e terceirizados. A pesquisa foi realizada sendo entregue um questionário em mãos dos entrevistados e sendo entregue no mesmo dia. 
A entrevista foi realizada no dia 03 de maio de 2017 em um órgão público da administração federal, foi formulado e aplicado um questionário com método misto e contendo 10 perguntas selecionadas sobre o tema, na modalidade respostas fechadas temos dois métodos aplicados, os quais foram escala forçada e o método Likert, e somente uma aberta, a idade, conforme mostra o modelo do questionário no apêndice deste estudo.

\section{ANÁLISE DOS RESULTADOS DO ESTUDO DE CASO}

Esta seção analisa a importância do endomarketing para a comunicação interna de um órgão público da Administração Federal.

A pesquisa foi realizada na coordenação de recursos logísticos, que faz parte de um setor do órgão que cuida da parte da logística, eles fazem a contratação de serviços e realização de obras mediante licitação, aquisição de material e formulação de licitação. A técnica utilizada foi a pesquisa bibliográfica e estudo de campo na modalidade estudo de caso, que permite uma maior obtenção de informações sobre o assunto.

Foi constatado um problema na comunicação interna da organização pública, onde os processos de licitação acabam demorando a serem liberados por falta de comunicação entre as partes, sendo que muitos serviços precisam ser resolvidos pelo teor de urgência, mas, acabam demorando, por falta de uma comunicação eficaz entre as partes envolvidas.

O Gráfico1 mostra o perfil dos entrevistados quanto ao sexo, idade e profissão. É uma análise importante para poder delimitar a porcentagem de funcionários e terceirizados entrevistados. Verifica-se haver equilíbrio apenas quanto à profissão, com a metade trabalhando no terceiro setor e a outra como servidor público.

Gráfico 1 - Perfil Socioeconômico dos entrevistados

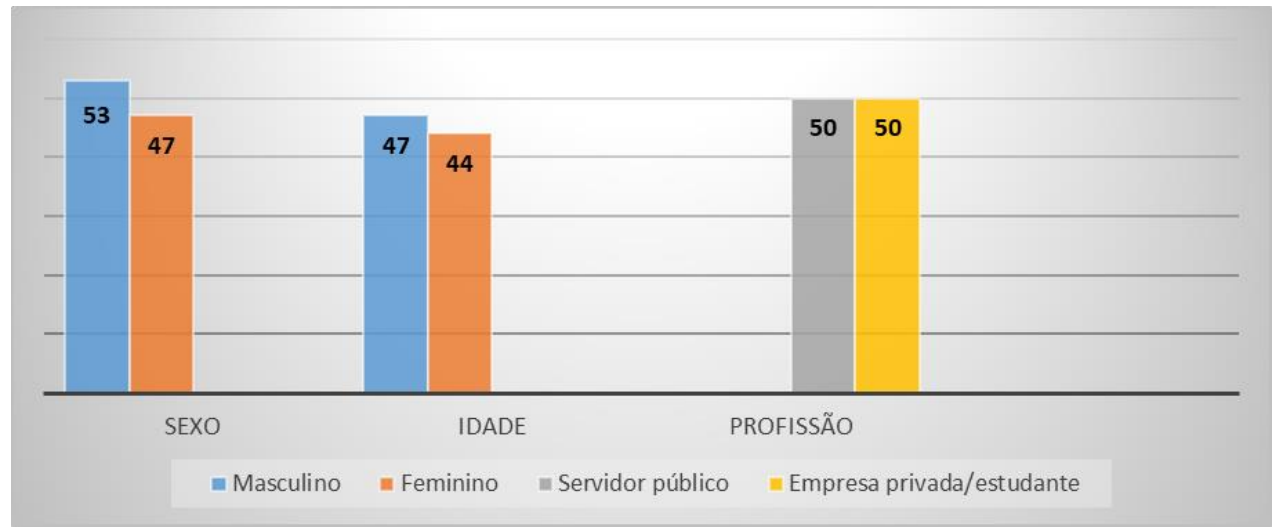

Fonte: Pesquisa de Campo (2017).

Observa-se que a maioria $53 \%$ dos entrevistados são homens. Em relação à idade, os homens estão com média de 47 anos e as mulheres, com 44. E quanto à profissão, metade é efetivo e a outra metade terceirizada. Sendo assim, como a idade dos colaboradores é acima dos quarenta anos, e o endomarkenting é uma área nova do marketing, acaba tendo um déficit de atualização com suas 
ferramentas e opções de trabalho, ou seja, há uma dificuldade maior dos funcionários visualizarem novos meios para poder trabalhar e se comunicar com outros setores e direto com o topo da pirâmide.

O Gráfico2 mostra informação sobre a importância que o funcionário vê em relação à comunicação e a sua produtividade.

Gráfico 2 - Comunicação e o nível de ruído interno

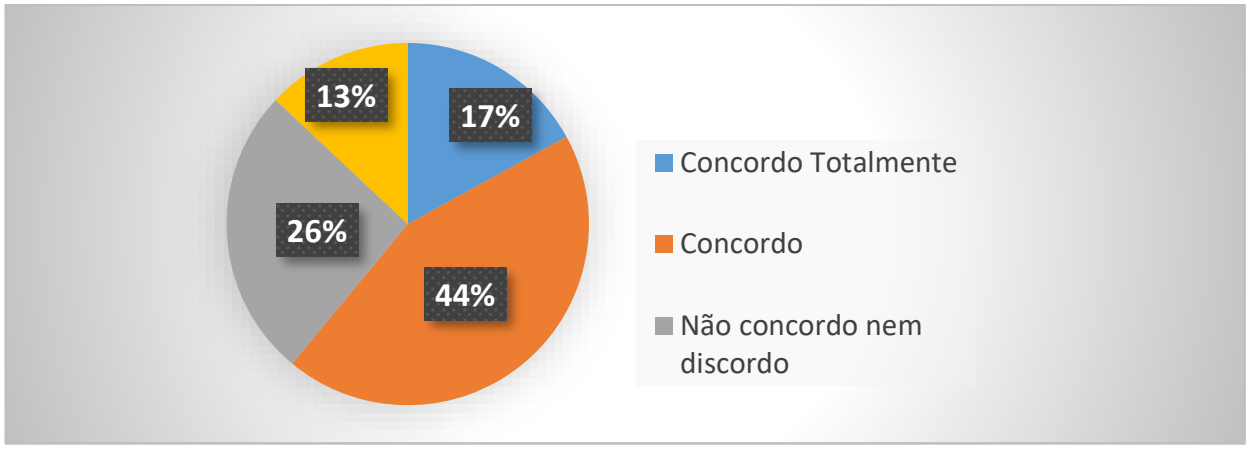

Fonte: Pesquisa de Campo (2017).

De acordo com a pergunta quatro do questionário aplicado, comunicação: nível de ruído interno (falha na comunicação) no setor influência na produtividade? Observa-se que $44 \%$ dos entrevistados afirmam que concordam, e $26 \%$ não concordam e nem discordam. Dentro disto, compreende-se que há um número relevante de pessoas que não percebem essa falha de comunicação.

O Gráfico 3 se refere à pergunta "capacidade técnica tem relevância para a comunicação interna". Pode-se observar que apenas $6 \%$ dos entrevistados discordam. Portanto, a capacidade técnica influencia positivamente na comunicação interna e que um número grande de funcionários tem conhecimento disto.

Gráfico 3 - Capacidade técnica e a relevância para comunicação interna

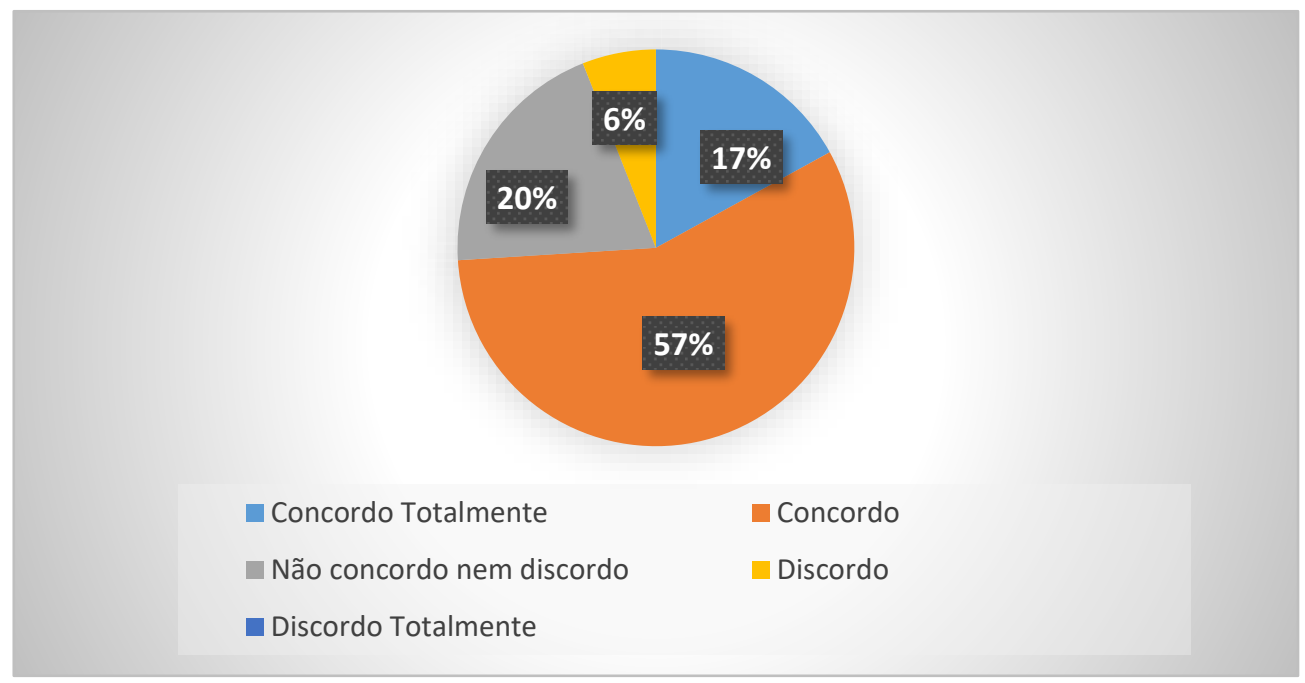

Fonte: Pesquisa de Campo (2017). 
O Gráfico 4 ainda se refere à comunicação, confirma que uma boa comunicação traz melhoria de qualidade do trabalho. A maioria $97 \%$ respondeu que concorda/concorda totalmente deste papel da comunicação. Isso ocorre porque a integração da comunicação é essencial para o bom andamento do órgão.

Gráfico 4 - A comunicação e melhora na qualidade do trabalho

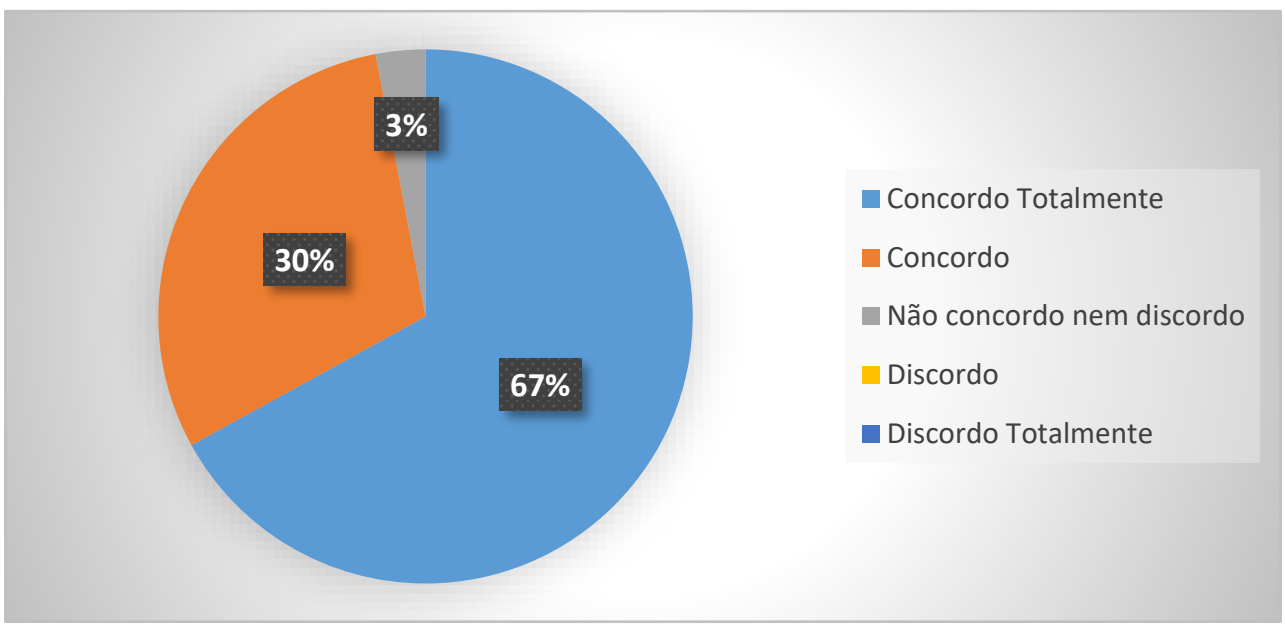

Fonte: Pesquisa de Campo (2017).

Os Gráficos 2, 3 e 4 buscaram mostrar o conhecimento que cada funcionário tem sobre a comunicação interna e sua importância. E, segundo a análise deles, pôde-se observar que muitos servidores públicos e terceirizados que trabalham no órgão, apesar de encontrarem um pouco de dificuldade com a interpretação das perguntas, têm, sim, uma noção de que a comunicação interna possui uma grande importância para tornar o ambiente mais agradável.

O Gráfico 5, mostra a habilidade que os superiores têm como comunicadores. Verificando que $47 \%$ discordam de que esses gestores têm habilidade de comunicadores. No entanto, a habilidade de comunicação precisa chegar na base da pirâmide, sem nenhum ruído.

\section{Gráfico 5 - A habilidade dos superiores como comunicadores}

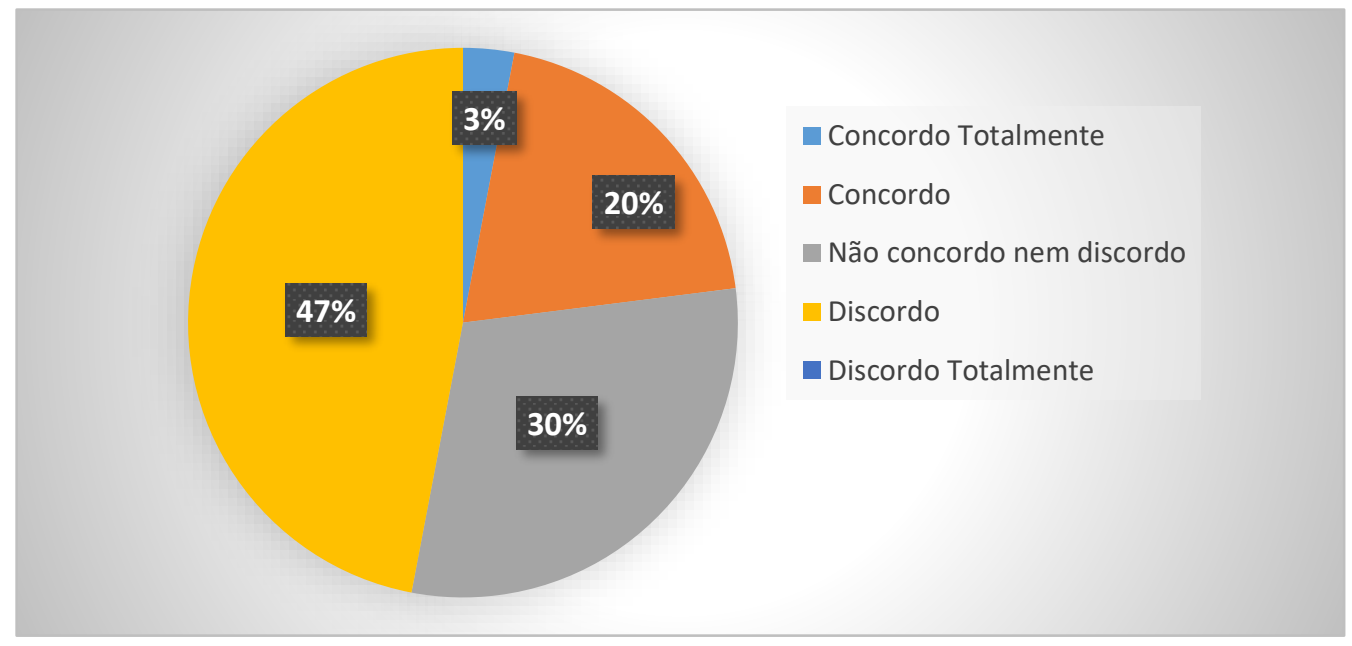

Fonte: Pesquisa de Campo (2017). 
O Gráfico 6 apresenta o grau de satisfação em que os funcionários têm em relação à comunicação com o seu setor. Observa-se que a maioria (53\%) discorda, e apenas (6\%) concordam. Logo, deduz-se que o grau de insatisfação com a comunicação interna no setor é grande. Essa insatisfação tem efeitos negativos no trabalho, pois, cada um dos funcionários é um comunicador.

Gráfico 6 - Satisfação da comunicação interna no trabalho

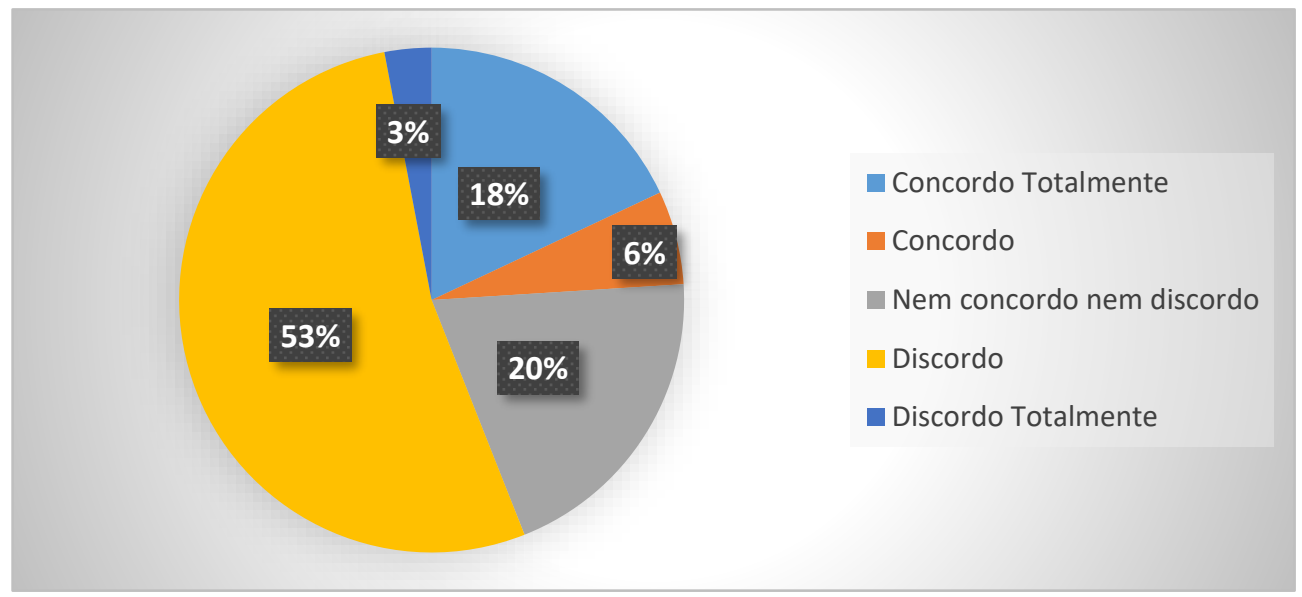

Fonte: Pesquisa de Campo (2017).

Finalmente, observa-se no Gráfico 7 que a maioria (63\%) dos entrevistados não sabe o que é endomarketing, enquanto $77 \%$ não participaram de palestra sobre o tema. Verifica-se que o endomarketing é uma estratégia não conhecida pelos entrevistados, sendo verificado que a palavra soou para alguns com um ar de estranheza no ambiente de trabalho.

Gráfico 7 - Conhecimento de endomarketing e participação em palestras

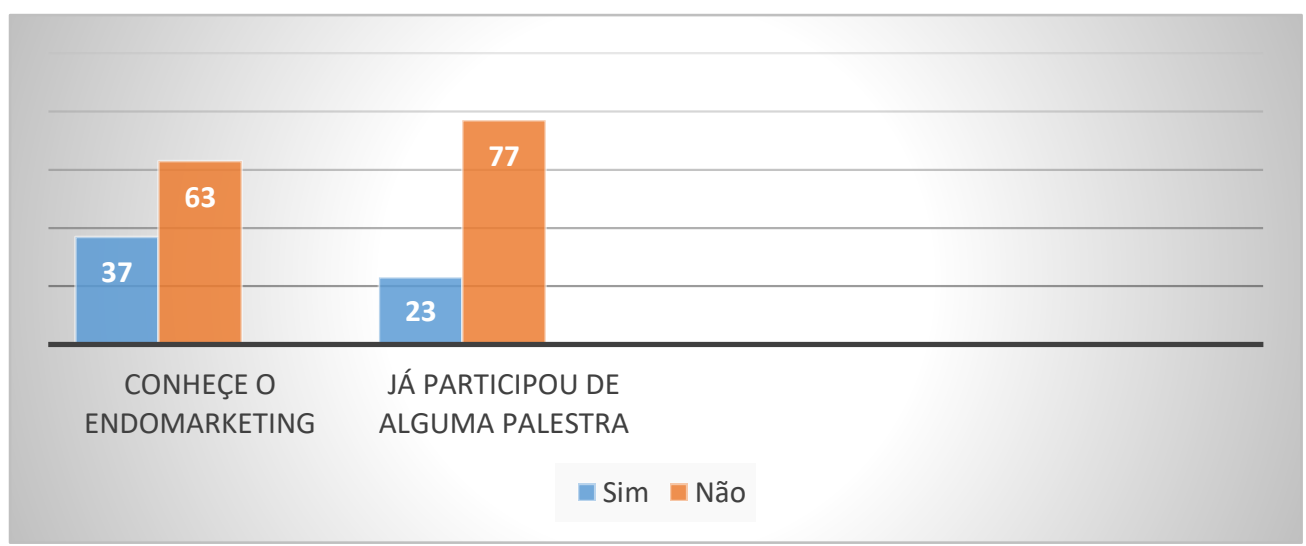

Fonte: Pesquisa de Campo (2017).

Logo, como a questão deste artigo é identificar e estudar a percepção dos colaboradores de um órgão federal sobre as ferramentas do endomarketing e comunicação, pode- se concluir que muitos funcionários não têm conhecimento sobre endomarketing, porém, uma grande parte dos funcionários entende que a comunicação interna é um ponto muito forte para que o trabalho tenha eficiência, 
e que seus superiores precisam de habilidade como comunicadores para o serviço prestado ser desenvolvido sem interrupções.

\section{CONCLUSÃO}

O estudo teve como objetivo identificar e estudar a percepção dos colaboradores de um órgão federal sobre as ferramentas do endomarketing e comunicação interna. Por meio do levantamento bibliográfico, feito em livros, teses, dissertações e trabalhos acadêmicos sobre o assunto e do questionário. Teve como metodologia uma pesquisa exploratória com as técnicas coleta de dados e estudo de campo na modalidade estudo de caso.

Baseado nos objetivos geral e específicos foi visto que o público interno deve ser primordialmente o alvo da organização pública, desta forma compreende-se que no órgão estudado, há uma falha de comunicação setorial, que este estudo identificou como causa a falta de habilidades de comunicação dos gestores superiores. A comunicação interna é um instrumento importante para o bom andamento de um órgão, e que para alcançar metas com eficiência, é preciso ter uma boa comunicação, do topo até a base. $O$ emprego dos canais de comunicação pode evitar os ruídos internos, pois todos os funcionários são também comunicadores.

Ficou evidenciado também que a maioria dos entrevistados não sabe ou não tem muito conhecimento sobre endomarketing e comunicação interna. Logo, a comunicação se torna falha ou insuficiente e o prazo em que um problema é detectado até a sua solução demora mais do que deveria.

Conclui-se que essa falha de comunicação interna faz com que as licitações não sejam feitas com eficiência dentro do seu prazo, levando assim a descontinuidade dos serviços solicitados, seja como reforma de elevadores, instalações prediais e até de materiais, o que acaba gerando um mal-estar na organização.

Logo, para que se possam sanar os problemas verificados, sugere-se a criação de uma política que seja voltada para os servidores e funcionários visando a melhora a comunicação, incluindo palestras e cursos sobre o tema. E assim criar elos sem ruídos, evitando distorções, tornando a comunicação mais rápida e sem falhas.

Desta maneira, um investimento em ferramentas de endomarketing é importante para que os funcionários possam atingir seus objetivos e desenvolver o seu trabalho com eficiência. A comunicação interna deve ser tratada com prioridade, os servidores e funcionários não podem ser vistos como espectadores, compreender que todos eles são atores e precisam estar envolvidos nos processos é primordial para a eficiência e eficácia na organização pública. Essa sincronia entre a comunicação e os comunicados, é essencial para a eficiência no trabalho. Essa fluidez na comunicação facilita a relação no trabalho, sendo assim, tem um papel importante para que a motivação seja alcançada, é que todos compartilhem da mesma visão.

Como direcionamento futuro, pode-se propor para a organização um maior conhecimento sobre esta ferramenta para que assim possa ampliar os seus recursos de comunicação interna e, com isso, ver melhor sua importância para um 
bom funcionamento dos serviços gerados no órgão. E pode-se propor também um estudo mais ampliado na área do endomarketing, pois por se tratar de um assunto relativamente novo, tanto na área do marketing como na de comunicação interna, muitas organizações públicas não conhecem e não sabem dos grandes benefícios que essa ferramenta pode trazer para o órgão público. 


\title{
The importance of endomarketing for internal communication
}

\begin{abstract}
This study aims to identify and study the employees' perception from a federal agency about the endomarketing's tools and communication. This is exploratory research whose data collection techniques used were bibliographical and field research, in the latest the data collection instrument was a questionnaire administered to thirty employees from a federal agency, effective employees and third sector. The analysis highlights that need improvement in the internal communication to the federal agency studied. And in relation to endomarketing, it's necessary use techniques so employees can get the best return on their sector, making them understand the importance of an improvement of communication between one sector and another, in order to be more efficient in the production process.
\end{abstract}

KEYWORDS: Endormarketing. Communication. Internal communication. 


\section{REFERÊNCIAS}

ANGELONI, Maria Terezinha. Comunicação nas Organizações da Era do Conhecimento. São Paulo: Editora Atlas, 2010.

BAHIA, Juarez. Introdução à Comunicação Empresarial. Rio de Janeiro, Editora Mauad, 1995.

BEKIN, Saul F. Conversando sobre endomarketing. São Paulo: Mackron Books. 1997.

Conversando sobre endomarketing. São Paulo: Makron Books,

2005.

Endomarketing: como praticá-lo com sucesso. São Paulo:

Pearson, 2006

BRUM, A. M. Endomarketing como estratégia de Gestão. Porto Alegre:L\&PM,1998.

Endomarketing de A a Z. Porto Alegre: Dora

Luzzatto, 2007.

Endomarketing de A a Z: como alinhar o

pensamento das pessoas à estratégia da empresa. São Paulo: Integrar e Editora, 2010.

Face a Face com o Endomarketing: O Papel

estratégico das Lideranças no Processo das Informações. Porto Alegre: L\&PM, 2005.

CASADO, T. As Pessoas na Organização. São Paulo: Editora Gente, 2002.

CERQUEIRA, W. Endomarketing: educação e cultura para a qualidade. Rio de Janeiro, RJ: Qualitymark, 1994.

DRUCKER, P. F. Sociedade Pós-Capitalista. São Paulo: Pioneira, 1993

FERREIRA FILHO, E.P.; PEREIRA, F. A.; PASSOS, G. S. A influência do

endomarketing e da comunicação interna na cultura organizacional. 2013. 
Disponível em: <http://www.aedb.br/seget/arquivos/artigos13/43318476.pdf>. Acesso em: 24 maio 2017.

FONSECA, J. J. S. Metodologia da pesquisa científica. Fortaleza: UEC, 2002. Apostila.

GARCIA, M. T. Marketing e comunicação para pequenas empresas: o marketing e a comunicação organizacional sem complicações, para novos empresários e aprendizes permanentes. São Paulo: Novate,2006

GIL, A. C. Como elaborar projetos de pesquisa. 3. ed. São Paulo: Atlas, 1994

. Métodos e técnicas de pesquisa social. 5.ed. São Paulo: Atlas, 1999.

GONSALVES, E. P. Iniciação à Pesquisa Cientifica. 2.ed. Campinas, SP. Editora Alínea, 2001.

GRÖNROOS, C. Marketing: Gerenciamento e serviços. 2.ed. Rio de Janeiro: Elsevier, 2003.

INKOTTE, A. L. Endomarketing: elementos para a construção de um marco teórico. 2000. Disponível em: <http://endomarketing.com/wpcontent/uploads/2014/10/publicacao-tese-alexandre-luz-inkotte.pdf $>$. Acesso em: 24 maio 2017.

KOTLER, P. Administração de Marketing: Análise, Planejamento, Implementação e Controle. 5 ed. São Paulo: Atlas, 1998.

Administração de Marketing: A edição do novo milênio. 10 edição São Paulo: Pretence Hall,2000.

Marketing 3.0: As forças que estão definindo o novo marketing centrado no ser humano. Rio de Janeiro: Elsevier, 2010 - 4.ed. impressão.

KOTLER, P.; KELLER, K. L. Administração de Marketing - A Bíblia do Marketing. 12.ed. São Paulo: Person - Prentice Hall, 2006.

MARCHIORI, M. Organização, Cultura e Comunicação: elementos para novas relações como o público interno. São Paulo, 1995, Dissertação (Mestrado), Escola de Comunicações e Artes da Universidade de São Paulo. 
MATTAR, F. N. Pesquisa de marketing: edição compacta. São Paulo: Atlas, 1996.

MAXIMIANO, A.C. A. Introdução a administração. São Paulo: Atlas, 1995.

PINHEIRO, D.; GULLO, J. Comunicação integrada de marketing, São Paulo, Atlas, 2005

RABAÇA, C. A.; BARBOSA, G.G. Dicionário de comunicação. 2. ed. Rio de Janeiro: Campus, 2001.

ROESCH, S. M. A. Projetos de estágio e de pesquisa em administração: guia para pesquisas, projetos, estágios e trabalho de conclusão de curso. São Paulo: Atlas, 2009.

TAVARES, M. Comunicação Empresarial e planos de comunicação: integrando teoria e prática. 3ed. São Paulo: Atlas, 2010.

Recebido: 02 dez. 2017

Aprovado: 12 dez. 2017

DOI: $10.3895 /$ gi.v13n4.7462

Como citar:

LIMA, S. C. M. G.; MELO, J. A. M. A importância do endomarketing para a comunicação interna. R. Gest. Industr., Ponta Grossa, v. 13, n. 4, p. 122-138, out./dez. 2017. Disponível em:

<https://periodicos.utfpr.edu.br/rgi $>$. Acesso em: XXX.

Correspondência:

José Airton Mendonça de Melo

SQN 314 I 501 - 70.77-090, Brasília, Distrito Federal, Brasil.

Direito autoral: Este artigo está licenciado sob os termos da Licença Creative Commons-Atribuição 4.0

Internacional.

(c) (1) 